\title{
Twenty years of the Schistosomiasis Programme at Fiocruz
}

Initially, I wish to express my sincere appreciation for the opportunity to give this talk, for two reasons. First of all, because talking to you in this wonderful baroque church is a privilege. This was possible for me only due to the Ecumenical Council II, which was held on the 1960s, therefore only a few decades ago, convoked by the eminent Pope Johannes XXIII of memorable remembrance. Secondly, because it is with great pleasure that I speak after another important "Pope": Dr. Lobato Paraense, who is admired by all of us, worthy of respect, applauded, and copied. His solid scientific formation and the accuracy he considers the scientific subjects, can explain why his works have so much contributed for Malacology to which he is really the Pope.

Therefore, I would like to thank Dr Omar dos Santos Carvalho, President of this Symposium, for this unique opportunity, which could be only offered to me by a friend and colleague of so many years. To Dr Omar must be credited a great part of the success attained by the Schistosomiasis Programme at Fiocruz.

\section{"Dear Colleague}

It is our pleasure to welcome you at the I Meeting on Schistosomiasis of the Researchers of the Oswaldo Cruz Foundation. In order to better explain what gave rise to this meeting, we think that a report, even though a succinct one, is necessary.

On October 1985, the Vice-President of Researches of the Oswaldo Cruz Foundation (Fiocruz), Dr Carlos M Morel, received a letter from Dr KE Mott, Head of the Program of Parasitic Diseases (schistosomiasis and other infections by trematodes), from the World Health Organization, suggesting that Fiocruz should be appointed a "WHO Collaborating Center for Basic and Applied Research on Schistosomiasis", and in order to support some activity related to the project the sum of US $\$ 2,000$ would be at Fiocruz disposal.

After the necessary arrangements, the project "Research and Training in Schistosomiasis" (TDR/WHO) was accepted and approved. On April 1986, Dr Morel delegated authority to the signatory of this report to undertake the task of "coordination and distribution of resources among the possible participant laboratories, definition of the prioritary goals and destination of the financial support, as well as the elaboration of a final report addressed to WHO".

After talking with various researchers, it was quite clear the need for a better knowledge about what has been carried out in the field of schistosomiasis, at Fiocruz. The lack of contact among the different research centers or even among the various laboratories at the Institute Oswlado Cruz is a lacuna that must be fulfilled.

On the other hand, the scientific policy to be followed at Fiocruz deserves to be discussed, and suggestions must be addressed to the Vice-Presidency of Researchs. For this purpose, we organized this meeting, and we all must work hard, since we have a term of only a day and a half to present several projects, to discuss then and the conclusions.

I would like to acknowledge Dr Morel for reposing considerable trust on me. I consider myself honoured by his attention, as well as by an additional financial support at our disposal. I am also grateful to Dr Omar dos Santos Carvalho, dedicated Secretary, who contributed so much to the accomplishment of this meeting, as well as to the researchers who readily accepted our invitation to participate in this meeting of so short-duration, but hopefully very fruitful.

Last, but not the least, I wish to express my appreciation to the World Health Organization for supporting this meeting, and also for the special deference choosing Fiocruz as one of its collaboration centers.

Naftale Katz

Laboratório de Esquistossomose, Centro de Pesquisas René-Rachou Belo Horizonte, 11 September 1986".

Afterwards, in 1987, the International Symposium on Schistosomiasis was held in Rio de Janeiro, simultaneously with the I National Meeting on Schistosomiasis, by decision of all researchers and guidance of Drs Miriam Tendler, Henrique Leonel Lenzi, Pedro Juberg, and Delir Corrêa Gomes.

It is interesting to note that this International Symposium was not mentioned as the first one, contrary to the I National Meeting, since we did not know whether we would be able to promote another one in the near future. Today we have already organized ten international symposia, without interruption, with a great and crescent participation of Brazilian and foreign researchers.

At the II Meeting of Researchers from Fiocruz, which was held on May 1989, the three regional centers (Research Center Aggeu Magalhães, in Recife; Research Center Gonçalo Muniz, in Salvador; Research Center René-Rachou, in Belo Horizonte) and the Institute Oswaldo Cruz/National School of Public Health, in Rio de Janeiro, had already the credentials as "WHO Collaboration Center for Research and Control of Schistosomiasis" of the World Health Organization. It must be emphasized that Fiocruz is the unique Institution in the whole world that received the title of "WHO Collaboration Center" for its four research centers. 
There were 36 researchers from Fiocruz dedicated to schistosomiasis who participated in that meeting. At that occasion was created the Schistosomiasis Programme, with the following objectives:

1. to define the exact function of the WHO Collaboration Centers, as well as to contribute for a better national and international technical cooperation in the area of schistosomiasis, providing information, services, and advice, giving research support and preparing human resources as well. The Collaboration Centers must be seen as an important channel for information, experience, and knowledge exchanges among the developing countries and to stimulate the integration process of various national activities;

2. to propitiate a better interchange among the researchers of the Collaboration Centers;

3. to afford an extensive discussion about activities carried out at the Foundation related to schistosomiasis mansoni;

It is worthwhile to mention that at this meeting was created the Management Committee composed by the Directors of the Regional Centers and of the IOC, as well as the following Scientific Committee:

$\begin{aligned} \text { Coordinator: } & \text { Naftale Katz } \\ \text { Basic area: } & \text { Henrique Leonel Lenzi } \\ & \text { Miriam Tendler } \\ & \text { Rodrigo Correa-Oliveira } \\ & \text { Zilton Andrade } \\ \text { Epidemiological area: } & \text { José Rodrigues Coura } \\ & \text { Frederico Simões Barbosa } \\ & \text { Otávio Pieri } \\ & \text { Luís Rey } \\ \text { Extern advisors: } & \text { Erney P Camargo } \\ & \text { Amaury Coutinho } \\ & \text { Aluísio Prata } \\ & \text { Heonir Rocha }\end{aligned}$

These meetings took place every other year and, in 1999, the Coordinator Naftale Katz sent in his resignation. Then, Otávio Pieri was chosen and he co-ordinated until 2002; after that Paulo Marcos Zech Coelho took over the coordination, and remains in charge of this position up to now.

Therefore, the two meetings (International Symposium and Meeting of Researchers) continued to take place, alternately, with results that may be considered very productive. At every other year the International Symposium was organized by one of the four Collaboration Centers localized in Rio de Janeiro, Belo Horizonte, Recife, and Salvador.

The number of researchers dedicated to the study of schistosomiasis increased significantly, reaching a plateau in the last years. The same can be said about the number of published papers, by sets of ten, every year.

Throughout these two decades, after the International Symposium, it was published a special issue of the excellent scientific journal Memórias do Instituto Oswaldo Cruz, containing the papers presented at the Symposium. As an activity related to the Program, it is worthwhile to mention the odd publications carried out by participants of the Program, with national circulation, as follows:

1. Molluscs of parasitological interest from Brazil, 1977.

2. Schistosomiasis - prevention is better than cure.

3. Brazilian Bibliography on Schistosomiasis - electronic edition quoting more than 3000 scientific papers published in Brazilian scientific journals (not always indexed journals) dealing with schistosomiasis, from 1908 untill 1990. It was the first time at Fiocruz that diskettes were used for divulgation of scientific information.

4. Who's Who in Schistosomiasis at Fiocruz, 1996.

5. Brazilian Bibliography of Theses on Schistosomiasis.

6. Morphological identification of Biomphalaria glabrata, B. tenagophila, and B.straminea, intermediary hosts of Schistosoma mansoni (CD-Rom - 2003)

7. Molluscs of Medical Importance in Brazil, 2005 (Book and CD-Rom)

The researchers of this Program have contributed for different research areas, as for example:

Diagnostic, Experimental, and Clinical Therapeutics

Immunology

Ultrastructure

Molecular Biology

Epidemiology

Health Education

Malacology, among others. 
Two courses were also organized: one for training of technicians (medium level), organized and directed by colleagues of the Research Center Aggeu Magalhães: Constança Simões Barbosa and Felipe Gonçalves; and another one (specialization level) in charge of colleagues from ENSP and IOC (Danielle Grynspan, Otávio Pieri, Silvana Thiengo, and Tereza Favre). More recently, a Referral Center of Schistosomiasis, at the Research Center René-Rachou was created, where several courses are offered to technicians from the Ministry of Health.

A book on schistosomiasis that is being edited by Omar dos Santos Carvalho, Henrique Leonel Lenzi, and Paulo Marcos Zech Coelho will be of great importance. These three researchers in collaboration with 33 others, pertaining to the Programme, are writing the book. It is a comprehensive publication with contributions of 112 authors, including different aspects of this important parasitosis.

Even at greatest risk of not mentioning important contributions, I would like to highlight some publications that can be immediately put at the public disposal:

- Serological diagnosis for the acute phase, using KLH as antigen

- Textbook for Health Education

- Natural molluscicide from the plant "Coroa de Cristo" (Euphorbia splenes)

- Diagnosis by PCR;

and for the near or distant future:

- Biological Control/Taim strain

- Vaccine: recombinant protein and its peptides.

The international symposia on schistosomiasis are the oldest and regular ones worldwide. For the organization of the 10th International Symposium on Schistosomiasis, among the already mentioned objectives, attention must be drawn to divulgation of works carried out in Brazil, since there are few citations of Brazilian papers by the international literature, for reasons that we do not know how to explain. We would like to note that, in the last years, there was a lack of support for researches on schistosomiasis in the American Continent.

In the African Continent, emphasis is led to schistosomiasis control, supported by either the European Community or by several foundations, namely Bill and Melissa Gates Foundation, Carter Foundation, among others.

In Asia, the great Chinese Power, the sleeping giant who has vigorously advanced in the last decades has also carried out substantial control programmes, as well as many important researches, using either its own resources or financial support provided by the World Bank. The same can be said about the Philippine Islands.

In Brazil, Fiocruz is the main institution for research on schistosomiasis. As far as schistosomiasis control is concerned, it has been carried out by the Ministry of Health in association with the State Secretary of Health and with the counties, in different states, with more or less intensity or extension, throughout many years. However, it is worthwhile to note that there is a consensus among Brazilian researchers and sanitarists regarding a marked decrease of the hepato-splenic forms of schistosomiasis in our country, in the last years.

Finally, I avail myself of this opportunity, with the presence of such outstanding Brazilian and foreign scientists from 14 different countries, to suggest the execution of a special Programme for Schistosomiasis Control for the American Continent, coordinated by the Pan-American Health Organization. Further, I would like to ask your agreement to this proposal.

As a matter of fact,

1. control, with the possibility of eradication in many Caribbean Islands, since it seems to be possible;

2. support to Venezuela concerning the work that has been carried out with significant results, diminishing nearly ten times the prevalence rate in that country;

3. to emphasize the need of a survey related to the prevalence in Brazil, since the last available data go back to 30 years ago;

4. special studies in Suriname, whose situation is poorly known.

In this way, a Programme for the American Continent, with similar objectives of the Schistosomiasis Programme by Fiocruz, could in a short period stimulate contacts among the researchers in the continent, promoting the control and increasing the researches, aiming at reaching, on the XXI Century, the control or even the eradication of schistosomiasis in the American Continent, attaining this goal more than 100 years after the discovery of this parasitosis in our Continent.

Thank you. 
